\title{
Las instituciones fiscales brasileñas: las reformas de Cardoso, 1995-2002
}

\author{
Fabio Giambiagi y M arcio R ond
}

$\mathrm{E}$

presente trabajo analiza la política fiscal aplicada en Brasil durante las dos administraciones del presidente Fernando Henrique Cardoso: 1995-1998 y 1998-2002. Subraya que, para el ajuste fiscal efectuado después de la crisis de 1998-1999, la política de austeridad aplicada por las autoridades fue tan importante como las reformas institucionales y estructurales. Señala que el deterioro que se produjo entre 1995 y 1998 obedeció principalmente a la reducción del balance primario y no a una mayor carga de intereses, mientras que en el período 1999-2002 el ajuste fiscal se debió en gran medida a un aumento de los ingresos, en circunstancias de que el gasto público primario del gobierno federal continuó aumentando en valores reales. Examina las perspectivas de sustentabilidad fiscal, y concluye que, para conservar la

- fgiambia@ipea.gov.br

Marcio Ronci

Economista Principal

Fondo Monetario Internacional (FMI)

- mronci@imf.org disciplina fiscal que costó tanto lograr, había que incorporar de manera permanente en las instituciones públicas la actitud de austeridad fiscal de las autoridades recientes. 
I

\section{Introducción}

Tras la adopción del Plan Collor en 1990, entre 1991 y 1994 el balance primario del sector público arrojó un excedente de 2,9\%. En cambio, después del Plan Real (junio de 1994), ${ }^{1}$ dicho balance registró un notable deterioro, que en promedio tuvo por consecuencia un déficit de 0,2\% del PIB en el período 1995-1998. En esos años, las autoridades recomendaron austeridad fiscal, pero las permanentes presiones por aumentar el gasto contrarrestaron con creces el aumento de los ingresos o el efecto de los recortes introducidos en otros gastos. Las propuestas de fijar límites máximos al déficit del sector público simplemente no lograron obtener el apoyo necesario.

A fines de 1998, Brasil enfrentó una profunda crisis externa y fiscal y suscribió un acuerdo de derecho de giro (stand-by) con el Fondo Monetario Internacional (FMI) para el período 1999-2001. Tras la fuerte devaluación del tipo de cambio en enero de 1999, el acuerdo fue reevaluado y en el 2001 se prorrogó hasta fines del 2002. En este contexto, hubo cambios profundos en el sistema político y en el período 1999-2002 el sector público arrojó un excedente primario medio sin precedentes de 3,6\% del PIB. ${ }^{2}$ Durante el segundo gobierno de Cardoso, el sector público operó con claras restricciones presupuestarias, consistentes en la fijación de un mínimo al excedente primario consolidado, para imponer el cual se modificó radicalmente la gestión de las finanzas públicas brasileñas. ${ }^{3}$

$\square$ Este artículo es una versión abreviada de Giambiagi y Ronci (2004), enriquecida con los comentarios formulados por Max Alier, Fabio Barbosa, Nigel Chalk, Martín Gilman, Vincent Moissinac, Laura Papi, Murilo Portugall, Hemant Shah y Evan Tanner. Los puntos de vista expresados aquí son los de los autores y no representan necesariamente los del FMI o del gobierno de Brasil.

${ }^{1}$ Los estudios relativos a la política fiscal brasileña de los decenios de 1980 y 1990 generalmente pasan por alto el año 1990, primer año de aplicación del Plan Collor, por estimar que fue atípico debido a los ingresos extraordinarios que se percibieron.

${ }^{2}$ Salvo indicación en contrario, en el presente trabajo el concepto de necesidades de financiamiento del sector público se relaciona más con los resultados nominales que con los resultados operativos. ${ }^{3}$ En este caso, las instituciones fiscales incluyen tanto el marco legal de la política fiscal como la actitud de las autoridades fiscales, la que obviamente contribuye al cumplimiento de la normativa. Cabe destacar que los arreglos institucionales no deben interpretarse como organizaciones convencionales o leyes y reglamentos de derecho positivo. Las instituciones son las reglas del juego —normas formales o informales - que utilizan los actores societales (North, 1990).
No obstante que la política fiscal ordinaria siguió basándose en la obtención de excedentes primarios mínimos y no en déficit nominales máximos, la verdad es que el incremento del gasto fiscal influyó directamente en el objetivo básico. Esto quedó de manifiesto en los esfuerzos de las autoridades por asegurar que el déficit nominal no pasara de ciertos límites, que a grandes rasgos correspondían a un sistema de fijar metas al déficit. Por ejemplo, el incremento de las tasas de interés en el 2001 y sus consecuencias para la proyección del pago de intereses más altos en el 2002 llevó a las autoridades a elevar la meta del excedente primario para ese año. Así, la meta oficial fijada inicialmente en 2,7\% del PIB se aumentó a 3,9\%, precisamente para compensar dicho incremento. ${ }^{4}$

Este artículo ofrece una reseña detallada de la evolución de las finanzas públicas durante los dos gobiernos del presidente Cardoso: 1995-1998 y 19992002. ${ }^{5}$ Sostenemos aquí que el cambio de actitud de las autoridades en materia de política fiscal frente a la crisis del balance de pagos de 1998-1999 tuvo tanta importancia como las reformas legales y constitucionales aprobadas a fines de la primera y comienzos de la segunda administración de Cardoso para lograr que el balance primario cambiara a 3,7\% del PIB entre 19951998 y 1999-2002. Las reformas efectuadas por el presidente Cardoso sólo pueden compararse en su alcance con las que hizo el presidente Castelo Branco (1964-1967), con la diferencia de que se introdujeron en condiciones políticas mucho más difíciles. ${ }^{6}$

De nuestra reseña surgen dos mensajes importantes. La causa principal más significante de dificultades

\footnotetext{
${ }^{4}$ La meta original consistente en lograr un superávit primario de $2,7 \%$ en el 2002 fue anunciada en el 2000, en el marco de una caída importante de las tasas de interés que, según lo previsto en ese momento, debía mantenerse en los años siguientes. Sin embargo, con posterioridad la tasa nominal del Sistema Especial de Liquidación y Custodia (SELIC), que a comienzos del 2001 bajó a 15\%, se elevó más de $20 \%$ en el 2002, lo que obligó a revisar las cifras proyectadas para el año siguiente.

${ }^{5}$ Si bien los datos para este estudio parten de 1994, por razones de espacio se centra la atención principalmente en el ajuste fiscal introducido después de 1998. Para una reseña de los diversos aspectos de la política fiscal en el período 1995-1998, véase Além y Giambiagi (1999). Para el período anterior al Plan Real en 1994, véase Giambiagi (1997).

${ }^{6}$ Véase una reseña de las reformas de Castelo Branco en Barbosa, Salazar y de Faro (1989) y en Skidmore (1988).
} 
fiscales en la primera administración de Cardoso fue el deterioro del balance primario y no el incremento de la carga de pago de intereses. En cambio, el ajuste fiscal en su segunda administración obedeció en gran medida al incremento de los ingresos, en circunstancias de que en los ocho años de sus dos gobiernos el gasto público básico del gobierno federal se elevó en valores reales. Estos aspectos del ajuste fiscal llevado a cabo por Cardoso ponen de relieve la necesidad de mantener la disciplina fiscal lograda con tanto esfuerzo y mejorar el ajuste en los próximos años. Un elemento clave para lograr la sostenibilidad fiscal ha sido la política de austeridad fiscal de las autoridades recientes, que debería ser un elemento permanente en las instituciones fiscales.
El artículo se divide en siete secciones. Tras esta breve introducción, la sección II pasa revista a la evolución de las necesidades de financiamiento del sector público en el período 1995-2002. La sección III destaca los principales factores y reformas estructurales del ajuste fiscal aplicado a partir de 1999. La sección IV trata sobre las fuentes de ingreso transitorias desde mediados del decenio de 1990. La sección V reseña la evolución de la deuda pública. La sección VI demuestra la importancia del cambio de postura de las autoridades respecto de la política fiscal. Finalmente, la sección VII contiene un resumen y conclusiones. Por su parte, el apéndice proporciona información acerca de la sustentabilidad de la deuda pública en el período 1995-2002.

\section{II}

\section{Panorama de las necesidades de financiamiento del sector público, 1995-2002}

En el comportamiento de las finanzas del sector público a contar de la adopción del Plan Real en 1994 es posible distinguir dos períodos — de 1995 a 1998 y de 1999 a 2002-, cada uno de los cuales corresponde a uno de los gobiernos del presidente Cardoso. La política económica confrontó dos grandes momentos críticos, el primero en 1995, cuando mermaron rápidamente los importantes excedentes del balance primario logrados en los años anteriores, y el segundo en 1999, cuando se llevó adelante un fuerte ajuste fiscal en todos los planos de gobierno (cuadro 1).

En lo que respecta a las principales cuentas fiscales, cabe señalar los cuatro hechos siguientes: ${ }^{7}$

\footnotetext{
${ }^{7}$ Es difícil comparar los resultados fiscales del primer gobierno de Cardoso con los del año en que se introdujo el Plan Real (1994), puesto que 1994 fue un año relativamente atípico. El superávit primario de 5,4\% del PIB registrado en 1994 fue muy superior al de $2,2 \%$ del PIB de los tres años anteriores. Esto se explica en gran medida por el hecho de que ese año los ingresos por concepto de impuestos se vieron favorecidos a la vez por la caída de la inflación y por la bonanza económica de los seis primeros meses de aplicación del plan, en circunstancias de que el gasto público se redujo. Por otra parte, en 1994, el excedente primario "sobre la línea" dado a conocer por el gobierno federal fue inferior casi en $1 \%$ del PIB al valor informado por el Banco Central — que representa la cifra oficial-, lo que nos hace pensar que la determinación del balance primario puede haber tropezado con algún problema metodológico, que pudo llevar a sobreestimarlo. Por esta razón, resolvimos comparar el promedio de los períodos.
}

Primero, hasta 1998, el déficit nominal del gobierno federal se fue acentuando gradualmente, en parte debido a que "heredó" deudas de los distintos estados, lo que en realidad significó una "socialización" de las pérdidas, y en parte porque la aplicación de una política monetaria restrictiva afectó con mayor fuerza el costo del financiamiento. Como consecuencia, las necesidades nominales de financiamiento del gobierno federal se elevaron de un tercio de las necesidades totales de financiamiento del sector público en 1995 a dos tercios en 1998.

Segundo, en comparación con el período 19911994, entre 1995 y 1998 los tres niveles de gobierno registraron un deterioro similar, seguido de un acentuado mejoramiento en 1999-2002 (cuadro 2).

Tercero, entre 1995 y 2002 los pagos de intereses alcanzaron un promedio de $7 \%$ del PIB y contribuyeron mucho al elevado déficit nominal promedio de $5,5 \%$ del PIB registrado en el mismo período. Si bien en los primeros años de vigencia del Plan Real la deuda pública total fue relativamente pequeña, sus intereses fueron altos debido a las fuertes presiones de que fueron objeto las tasas de interés real, en parte por el riesgo que involucraba otorgar préstamos al gobierno en un ambiente de creciente deterioro fiscal y en parte por la necesidad de atraer financiamiento externo para 
CUADRO 1

Brasil: Necesidades de financiamiento del sector público (En porcentajes del $P I B)^{a}$

\begin{tabular}{|c|c|c|c|c|c|c|c|c|c|}
\hline & 1994 & 1995 & 1996 & 1997 & 1998 & 1999 & 2000 & 2001 & 2002 \\
\hline \multicolumn{10}{|l|}{ Necesidades de financiamiento } \\
\hline del sector público & $-27,0$ & $-7,3$ & $-5,9$ & $-6,1$ & $-7,5$ & $-5,8$ & $-3,6$ & $-3,6$ & $-4,6$ \\
\hline Gobierno federal & $-10,2$ & $-2,4$ & $-2,6$ & $-2,6$ & $-4,9$ & $-2,7$ & $-2,3$ & $-2,1$ & $-0,8$ \\
\hline Estados y municipios & $-12,1$ & $-3,6$ & $-2,7$ & $-3,0$ & $-2,0$ & $-3,1$ & $-2,1$ & $-2,0$ & $-3,8$ \\
\hline Empresas públicas & 4,7 & 1,3 & 0,6 & 0,4 & 0,5 & $-0,1$ & $-0,7$ & $-0,6$ & 0,0 \\
\hline Balance primario & 5,2 & 0,3 & $-0,1$ & $-1,0$ & 0,0 & 3,2 & 3,5 & 3,6 & 3,9 \\
\hline Gobierno federal & 3,3 & 0,5 & 0,4 & $-0,3$ & 0,6 & 2,3 & 1,9 & 1,8 & 2,4 \\
\hline Gobierno federal y Banco Central & 3,1 & 0,5 & 0,5 & 0,0 & 1,3 & 3,3 & 2,8 & 2,9 & 3,6 \\
\hline Seguridad social ${ }^{\mathrm{b}}$ & 0,2 & 0,0 & $-0,1$ & $-0,3$ & $-0,8$ & $-1,0$ & $-0,9$ & $-1,1$ & $-1,3$ \\
\hline Estados y municipios & 0,8 & $-0,2$ & $-0,5$ & $-0,7$ & $-0,2$ & 0,2 & 0,5 & 0,9 & 0,8 \\
\hline Empresas públicas & 1,2 & $-0,1$ & 0,1 & 0,1 & $-0,4$ & 0,7 & 1,1 & 0,9 & 0,7 \\
\hline Pago de intereses & $-32,2$ & $-7,5$ & $-5,8$ & $-5,1$ & $-7,5$ & $-9,0$ & $-7,1$ & $-7,2$ & $-8,5$ \\
\hline Gobierno federal & $-13,4$ & $-2,9$ & $-2,9$ & $-2,3$ & $-5,5$ & $-5,0$ & $-4,1$ & $-3,9$ & $-3,1$ \\
\hline Estados y municipios & $-12,8$ & $-3,4$ & $-2,2$ & $-2,3$ & $-1,8$ & $-3,4$ & $-2,6$ & $-2,9$ & $-4,6$ \\
\hline Empresas públicas & $-5,9$ & $-1,3$ & $-0,7$ & $-0,5$ & $-0,2$ & $-0,6$ & $-0,3$ & $-0,4$ & $-0,7$ \\
\hline \multicolumn{10}{|l|}{ Partidas pro memoria } \\
\hline Ajuste del balance (flujos) & $\ldots$ & $\ldots$ & $-1,9$ & 1,8 & $-1,0$ & $-6,9$ & 0,1 & $-3,9$ & $-7,6$ \\
\hline Privatizaciones & $\ldots$ & $\ldots$ & 0,1 & 1,9 & 1,3 & 0,5 & 1,4 & $-0,4$ & $-0,8$ \\
\hline Otros & $\ldots$ & $\ldots$ & $-2,0$ & $-0,1$ & $-2,3$ & $-7,4$ & $-1,3$ & $-3,5$ & $-6,8$ \\
\hline Ajuste de la deuda interna & $\ldots$ & $\ldots$ & 0,0 & 0,0 & $-0,4$ & $-3,8$ & $-0,4$ & $-1,4$ & $-3,6$ \\
\hline Ajuste de la deuda externa & $\ldots$ & $\ldots$ & $-0,1$ & $-0,1$ & $-0,3$ & $-2,7$ & $-0,6$ & $-0,6$ & $-3,6$ \\
\hline Otros ajustes & $\ldots$ & $\ldots$ & $-1,9$ & 0,0 & $-1,6$ & $-0,9$ & $-0,3$ & $-1,5$ & 0,4 \\
\hline
\end{tabular}

Fuente: Banco Central de Brasil.

a El signo menos indica déficit.

b Entradas por concepto de seguridad social, menos pago de prestaciones.

CUADRO 2

Brasil: Balance primario del sector público

(Promedio de los períodos, en porcentajes del PIB) ${ }^{a}$

\begin{tabular}{lcrr}
\hline & $1991-1994$ & $1995-1998$ & $1999-2002$ \\
\hline Balance primario & 2,9 & $-0,2$ & 3,6 \\
Gobierno federal & 1,6 & 0,3 & 2,1 \\
$\quad$ Gobierno federal y Banco Central & 1,0 & 0,6 & 3,2 \\
$\quad$ Seguridad social & 0,6 & $-0,3$ & $-1,1$ \\
Estados y municipios & 0,7 & $-0,4$ & 0,6 \\
Empresas públicas & 0,7 & $-0,1$ & 0,9 \\
$\quad$ Federales & 1,1 & 0,2 & 0,7 \\
Estaduales y municipales & $-0,4$ & $-0,3$ & 0,2 \\
\hline
\end{tabular}

Fuente: Banco Central de Brasil.

a El signo menos indica déficit.

b Entradas por concepto de seguridad social, menos pago de prestaciones.

cubrir los déficit de la cuenta corriente externa después de las crisis asiática y rusa. ${ }^{8}$ Utilizando como deflactor

\footnotetext{
${ }^{8}$ Véase Ferreira y Tullio (2002, p. 153).
}

el índice nacional de precios al consumidor en su concepto amplio, en el período 1995-1998 la tasa bruta de interés real del Sistema Especial de Liquidación y Custodia (SELIC) alcanzó un promedio de $22 \%$. Posteriormente, se redujo a un promedio de $10 \%$ entre 1999 y 


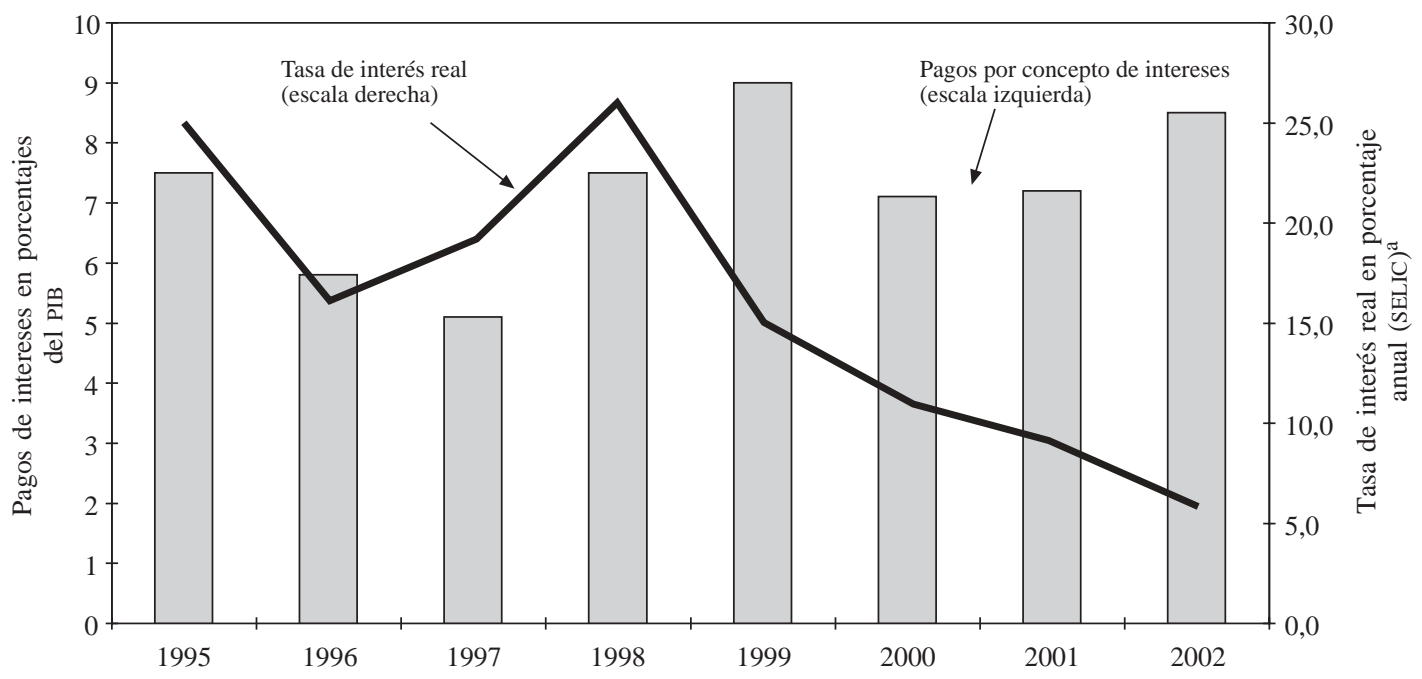

Fuente: Banco Central de Brasil.

a Tasa de SELIC: Tasa del Sistema Especial de Liquidación y Custodia.

2002. Sin embargo, como este valor inferior se aplicaba a una deuda pública mucho más cuantiosa, combinado con los efectos de la devaluación cambiaria se tradujo en que debieran pagarse elevadas sumas en intereses (gráfico 1). ${ }^{9}$

Cuarto, el hecho de que en las cuentas fiscales apareciera una variable que sería fundamental para la dinámica de la deuda pública —el "balance general ajustado"- que se remonta al período 1995-1998. ${ }^{10}$ Esta variable involucra factores "bajo la línea" que no afectan los flujos para satisfacer las necesidades de financiamiento del sector público y que modifican el valor de la deuda pública. Las privatizaciones reducen la deuda pública, mientras que la contabilización de deudas que no se habían registrado y la redenominación de la deuda pública expresada en moneda extranjera debido a la devaluación del tipo de cambio aumentan el monto de la deuda. En conjunto, estos efectos dieron lugar a que entre 1994 y 2002 la deuda pública tuviese una variación acumulada de 19 puntos porcentuales del PIB.

\section{III}

\section{El ajuste y las reformas fiscales}

Como se dijo en la sección anterior, los pagos de intereses no explican la baja del déficit nominal, que en el período 1995-2002 siguió siendo elevado. A continua-

\footnotetext{
${ }^{9}$ Véase en Garcia y Didier (2000) un análisis de los factores determinantes de las tasas de interés en Brasil.

${ }^{10}$ En rigor, el reconocimiento de deudas antiguas que antes no se contabilizaban en el balance ajustado comenzó en el gobierno de Collor, expresando las obligaciones en las denominadas "monedas de privatización", esto es, deudas que se aceptaban como medios de pago en la venta de empresas estatales.
}

ción examinamos las causas del ajuste fiscal a partir de 1999, centrándonos en los resultados del balance primario, que no incluye los pagos de intereses. A nivel del gobierno federal, los ingresos tributarios aumentaron de manera significativa, mientras que el gasto no financiero se elevó sostenidamente. En los planos estadual y federal, los cambios estructurales e institucionales se tradujeron en una mejora gradual del balance primario después de 1998. En las empresas públicas, dicho balance también ha mejorado mucho 
desde 1999, debido principalmente a los resultados obtenidos por la empresa petrolera estatal (Petrobras).

En los dos gobiernos de Cardoso, y en especial durante el segundo, se realizaron importantes reformas estructurales e institucionales en cinco campos diferentes, a saber, el sistema fiscal estadual y muni- cipal; la privatización de las empresas públicas; la seguridad social; el sistema financiero, y los procedimientos presupuestarios (recuadro 1). Estas reformas guardaron estrecha relación con la capacidad de las autoridades para poner en práctica un ajuste fiscal en 1999-2002.

\section{Recuadro 1 \\ Las Reformas fiscales de CARdoso}

\section{El sistema fiscal de los estados y de los municipios}

No hay duda alguna de que el sistema fiscal de los estados y de los municipios experimentó un cambio profundo, que se caracterizó por la eliminación de diversas fuentes de desequilibrios fiscales de naturaleza estructural. Entre los cambios observados, cabe señalar los siguientes:

- la privatización de la mayoría de los bancos de propiedad de los gobiernos estaduales, lo que puso fin al financiamiento de las tesorerías estaduales;

- la aplicación de severas restricciones a la práctica de otorgar anticipos sobre los recursos presupuestarios, que de hecho eran mecanismos para obtener créditos del sistema financiero;

- el bloqueo de los mecanismos para la emisión de créditos precautorios por el sistema judicial (esto es, garantías de pago por el sector privado de las sumas ordenadas pagar en virtud de sentencias judiciales), que durante parte del decenio de 1990 a menudo fueron utilizadas para otros fines y contribuyeron al deterioro fiscal de los gobiernos estaduales;

- el refinanciamiento de las deudas estaduales y municipales mediante la federalización de los títulos de la deuda emitidos por ellos a cambio de comprometer en garantía ("colateralizar") sus ingresos futuros. Esta medida indujo a los gobiernos estaduales a efectuar ajustes fiscales para amortizar su deuda en un plazo de 30 años (en la mayoría de los casos comprometiendo un máximo de $30 \%$ de los ingresos) bajo pena de que el gobierno federal se valiera de sus facultades legales para retener las transferencias constitucionales e incluso se apropiara de una parte de los ingresos provenientes del impuesto sobre circulación de mercaderías y de servicios (ICMS);

- La Ley de responsabilidad fiscal (ley complementaria $\mathrm{N}^{\circ} 101$ de 4 de mayo del 2002) estableció, entre otras cosas, montos máximos a los gastos por concepto de remuneraciones de acuerdo con los ingresos totales de los gobiernos estaduales y federal; restringió las atribuciones de las autoridades, especialmente en años de elecciones; promovió la aplicación de normas de transparencia para informar de las cuentas del sector público, y prohibió nuevos refinanciamientos por el gobierno federal de la deuda de los estados y de los municipios.

\section{La privatización de las empresas públicas}

Las privatizaciones también constituyeron una importante reforma estructural. Eliminaron lo que hasta entonces había sido una posible fuente de presiones sobre el gasto público, asociada a las inversiones de estas empresas. Si éstas hubiesen vuelto a los altos niveles de inversión de principios de la década de 1980, habrían ejercido fuerte presión sobre la deuda pública. Al mismo tiempo, la venta de empresas públicas que generalmente habían operado a pérdida, como el Ferrocarril Federal, eliminó lo que había sido fuente permanente de problemas en las cuentas del sector público. Por lo que respecta a los distintos gobiernos estaduales, ellos se desprendieron de varias empresas deficitarias y, por el propio proceso de preparación de estas empresas para la privatización, vieron mejorar notablemente la gestión de las empresas que siguieron siendo estatales.

\section{La seguridad social}

La reforma constitucional del sistema de seguridad social, aprobada en 1998, hizo posible:

- establecer una edad mínima de jubilación para los funcionarios públicos y aumentar gradualmente la edad de jubilación de aquellos que tenían menos años de servicio; 
- contratar nuevos funcionarios públicos con arreglo al sistema general de seguridad social, sin las prerrogativas del sistema de pensiones de la administración pública, y establecer fondos de pensiones para los nuevos funcionarios;

- eliminar la fórmula de cálculo de las pensiones de jubilación contemplada en la constitución federal, con lo cual se crearon las condiciones para establecerla por ley. Esto se hizo efectivo en el período 1999-2002 al promulgarse la ley sobre el "factor de bienestar social", ${ }^{\text {a }}$ que contribuyó a poner coto al déficit de la seguridad social, ya que la nueva fórmula de cálculo de las pensiones desalentó las jubilaciones anticipadas y la declaración de ingresos inferiores a los reales.

\section{El sistema financiero}

Por la vía de fortalecer el sistema financiero, las reformas a este sistema abordaron posibles fuentes de déficit.

Las reformas en este campo incluyeron:

- la aprobación del Programa de Estímulo a la reestructuración y el fortalecimiento del sistema financiero nacional (PROER);

- la privatización de diversos bancos estaduales, en varios casos tras su adquisición por el gobierno federal, con lo cual se puso fin a una de las principales fuentes de desequilibrio fiscal en los decenios de $1980 \mathrm{y}$ 1990;

- la ampliación de la apertura del sector financiero al capital extranjero, con la venta de diversos bancos a transnacionales bancarias, con lo cual aumentó la competencia dentro del sistema bancario;

- el requisito exigido por el Banco Central de que los bancos aplicaran criterios más estrictos para el otorgamiento de créditos, lo que se tradujo en un apreciable mejoramiento de la solidez del sistema y la reducción de su exposición al riesgo;

- el fortalecimiento de los bancos de propiedad federal mediante la capitalización, la aplicación de normas sobre las actividades no redituables y la aplicación de las recomendaciones del Comité de Basilea.

\section{Los procedimientos presupuestarios}

La Ley de responsabilidad fiscal también modificó los procedimientos presupuestarios previstos en la Ley de directrices presupuestarias que aprueba el Congreso en junio de cada año. Esta última ley establece los parámetros para preparar el presupuesto general del gobierno federal del año siguiente, que se presenta al Congreso en agosto. La Ley de responsabilidad fiscal dispuso que las directrices presupuestarias debían incluir no sólo la principal meta básica de resultados para el Presupuesto general del gobierno federal, sino también las metas de los dos años siguientes. Este principio de marco presupuestario de mediano plazo ha dado buenos resultados como restricción presupuestaria: limita el gasto total y apunta a que los gastos adicionales dependan de los recursos disponibles. El presupuesto de mediano plazo es una auténtica innovación institucional en Brasil, que a lo largo de la historia a menudo ha eludido las restricciones presupuestarias.

a Véase Ornelas y Vieira (1999).

\section{El gobierno federal}

El cuadro 3 muestra el desglose de los ingresos y gastos del balance primario del gobierno federal desde 1994 hasta 2002, basado en las estadísticas que publica el Ministerio de Hacienda. ${ }^{11}$ En el cuadro sobresalen dos tendencias:

\footnotetext{
${ }^{11}$ Los datos se refieren a las estadísticas "sobre la línea" establecidas por la Secretaría Nacional del Tesoro, que también incluyen los balances de seguridad social y del Banco Central. La diferencia entre esa cifra y el balance primario "bajo la línea" que publica el Banco Central, medida por las necesidades de financiamiento me-
}

- En el período considerado, los ingresos fiscales aumentaron apreciablemente. Los ingresos brutos del gobierno federal subieron de un promedio de 16,5\% del PIB en 1991-1994 a 22,6\% entre 1992 y 2002 .

- Al mismo tiempo, los gastos no financieros del gobierno federal se elevaron de manera considerable. Contribuyeron a este aumento todas las categorías principales. Entre 1991 y 1994 y entre 1999

nos el interés nominal, se ajusta de acuerdo con la "discrepancia estadística", que se asemeja a la estadística de errores y omisiones del balance de pagos. 


\begin{tabular}{|c|c|c|c|c|c|c|c|c|c|c|c|}
\hline & \multirow[b]{2}{*}{1995} & \multirow[b]{2}{*}{1996} & \multirow[b]{2}{*}{1997} & \multirow[b]{2}{*}{1998} & \multirow[b]{2}{*}{1999} & \multirow[b]{2}{*}{2000} & \multirow[b]{2}{*}{2001} & \multirow[b]{2}{*}{2002} & \multicolumn{3}{|c|}{ Promedios del período } \\
\hline & & & & & & & & & 1991-1994 & 1995-1998 & $1999-2002$ \\
\hline Total ingresos & 18,3 & 17,5 & 18,4 & 20,1 & 21,7 & 21,5 & 22,7 & 24,4 & 16,5 & 18,6 & 22,6 \\
\hline Transferencias a estados y municipios & 2,8 & 2,7 & 2,8 & 3,0 & 3,6 & 3,7 & 3,9 & 4,3 & 2,7 & 2,8 & 3,9 \\
\hline Ingresos netos & 15,5 & 14,7 & 15,6 & 17,2 & 18,1 & 17,8 & 18,8 & 20,1 & 13,8 & 15,8 & 18,7 \\
\hline Gastos no financieros & 14,8 & 14,5 & 15,4 & 16,6 & 16,0 & 15,9 & 17,1 & 17,9 & 12,4 & 15,3 & 16,7 \\
\hline Gastos de la nómina & 5,6 & 5,2 & 4,8 & 5,0 & 5,1 & 5,0 & 5,4 & 5,6 & 4,4 & 5,2 & 5,3 \\
\hline Prestaciones de seguridad social & 5,0 & 5,3 & 5,4 & 5,8 & 6,0 & 6,0 & 6,3 & 6,7 & 4,4 & 5,4 & 6,3 \\
\hline Otros gastos corrientes y de capital ${ }^{b}$ & 4,2 & 4,0 & 5,3 & 5,7 & 4,9 & 4,9 & 5,4 & 5,6 & 3,7 & 4,8 & 5,2 \\
\hline Discrepancia estadística $^{c}$ & $-0,1$ & 0,2 & $-0,5$ & 0,0 & 0,2 & $-0,1$ & 0,1 & 0,2 & 0,2 & $-0,1$ & 0,1 \\
\hline Balance primario & 0,5 & 0,4 & $-0,3$ & 0,6 & 2,3 & 1,9 & 1,8 & 2,4 & 1,6 & 0,3 & 2,1 \\
\hline Gobierno federal y Banco Central de Brasil & 0,5 & 0,5 & 0,0 & 1,4 & 3,3 & 2,8 & 2,9 & 3,7 & 1,0 & 0,6 & 3,2 \\
\hline Seguridad social & 0,0 & $-0,1$ & $-0,3$ & $-0,8$ & $-1,0$ & $-0,9$ & $-1,1$ & $-1,3$ & 0,6 & $-0,3$ & $-1,1$ \\
\hline
\end{tabular}

Fuente: Secretaría de Política Económica, Ministerio de Hacienda.

a El signo menos indica déficit.

b Incluye el balance primario del Banco Central de Brasil.

c El valor positivo indica incremento del superávit del balance primario.

y 2002, los gastos por concepto de remuneraciones (debido sobre todo al peso relativo de las pensiones de los trabajadores jubilados), las prestaciones de seguridad social y "otros gastos" (excluidos las transferencias a estados y municipios, los aportes de nómina y las prestaciones de seguridad social) se acrecentaron en 0,9 , en 1,8 y en 1,5 puntos porcentuales del PIB, respectivamente. Además, en los mismos períodos las transferencias a los estados y los municipios se elevaron en 1,2\% del PIB.

\section{a) Los ingresos fiscales}

Las dos fuentes principales de ingresos adicionales del gobierno federal eran: i) la contribución provisoria sobre el movimiento financiero (CPMF) que fue introducida en forma de impuesto (IPMF) a fines de 1993, y posteriormente eliminada y restablecida en diversas oportunidades; ii) la Contribución para el Financiamiento de la Seguridad Social (COFINS), asociada al incremento de la tasa impositiva y a una serie de sentencias judiciales que favorecieron al gobierno, gracias a lo cual se venció la resistencia a introducir este impuesto en la primera parte del decenio. ${ }^{12} \mathrm{La}$ suma de ambas contribuciones representa cerca de dos tercios de la variación de los ingresos registrada entre

12 Desde el punto de vista del gobierno federal, se justificaba dar prioridad a un ajuste mediante estas contribuciones y no mediante
1991-1994 y 1999-2002. Al mismo tiempo, los ingresos provenientes del Impuesto a los Productos Industriales (IPI) bajaron sostenidamente (cuadro 4).

En 1999-2000 se detuvo el crecimiento del gasto federal como proporción del PIB, para reanudarse en el período 2001-2002. A continuación se ofrece un análisis detallado del gasto no financiero. ${ }^{13}$

\section{b) Los gastos en remuneraciones (de nómina)}

Los gastos del gobierno federal por concepto de remuneraciones aumentaron de 18.500 millones de reales en 1995 a 33.200 millones de reales en el 2001 en valores reales, pese a que entre ambas fechas se "congelaron" los salarios de la administración pública: el primer reajuste lineal de éstos desde 1995 sólo se produjo en el 2002. Esta aparente contradicción se debió a que, con el tiempo, casi todas las categorías se vieron beneficiadas, entre otras cosas, por revisiones de las carreras, "ajustes a la curva" o ascensos.

gravámenes como el impuesto sobre los ingresos o el Impuesto sobre los Productos Industriales (IPI). En el caso de las contribuciones, la totalidad del aumento de los ingresos corresponde al gobierno federal, ya que no se comparten con los estados y los municipios. En cambio, en el caso del impuesto sobre los ingresos y del IPI, el incremento neto de las entradas del gobierno federal es mucho más pequeño debido a que casi la mitad de los ingresos deben entregarse al fondo de participación de los estados y de los municipios.

${ }^{13}$ Véase en Velloso (1997) una reseña de la situación fiscal a comienzos de la vigencia del Plan Real. 


\begin{tabular}{|c|c|c|c|}
\hline & 1991-1994 & $1995-1998$ & $1999-2002$ \\
\hline Total ingresos ${ }^{c}$ & 11,9 & 13,2 & 16,6 \\
\hline Impuesto de importación & 0,4 & 0,7 & 0,7 \\
\hline IPI & 2,3 & 2,0 & 1,6 \\
\hline Impuesto a la renta & 3,7 & 4,5 & 5,6 \\
\hline Personal & 0,2 & 0,3 & 0,3 \\
\hline Empresas & 1,1 & 1,5 & 1,7 \\
\hline Trabajo personal & 1,3 & 1,5 & 1,7 \\
\hline Rentabilidad del capital & 0,7 & 0,8 & 1,2 \\
\hline Otros & 0,3 & 0,4 & 0,7 \\
\hline IPMF/CPMF & 0,3 & 0,4 & 1,3 \\
\hline IOF & 0,7 & 0,4 & 0,3 \\
\hline COFINS & 1,5 & 2,2 & 3,7 \\
\hline PIS/PASEP & 1,1 & 0,9 & 1,0 \\
\hline Contribución sobre las utilidades netas & 0,7 & 0,9 & 0,8 \\
\hline Contribuciones de seguridad social de la administración pública & 0,1 & 0,3 & 0,3 \\
\hline Otros & 1,2 & 0,9 & 1,3 \\
\hline \multicolumn{4}{|l|}{ Partidas pro memoria } \\
\hline Carga tributaria & 25,7 & 28,8 & 32,8 \\
\hline ICMS & 6,7 & 7,0 & 7,6 \\
\hline
\end{tabular}

Fuente: Secretaría de Ingresos Federal, Instituto Brasileño de Geografía y Estadística (IBGE).

a $\quad$ IPI $=$ Impuestos sobre los productos industrializados. IPMF/CPMF = Impuestos provisorios sobre el movimiento financiero/contribución provisoria sobre el movimiento financiero. $\mathrm{IOF}=$ Impuestos sobre operaciones financieras.

COFINS = Contribución para el financiamiento de la seguridad social. PIS/PASEP = Programa de Integración Social y de formación del Patrimonio del Servidor Público. ICMS = Impuesto sobre circulación de mercaderías y de servicios.

b Los datos difieren de los del cuadro 3 debido a la aplicación de metodologías contables diferentes.

c No incluye contribuciones de seguridad social.

Otro componente importante del gasto total del gobierno en remuneraciones fueron los gastos irrogados por el pago de las pensiones a los jubilados del sector público. En total, esos gastos se elevaron a 5,6\% del PIB en el 2002, mientras que en 1994 alcanzaron a $5 \%$ del PIB, porque la reducción del gasto por concepto de remuneraciones de los funcionarios en servicio activo se contrarrestó con creces por el aumento del gasto en los pensionados del sector público, en especial el personal militar. La combinación del envejecimiento de la población con la existencia de normas de jubilación indulgentes para los funcionarios públicos contribuyó significativamente a los gastos de nómina. ${ }^{14}$

\section{c) Las prestaciones de seguridad social}

Otro elemento fundamental del gasto público eran los gastos por concepto de seguridad social. Tras la

\footnotetext{
${ }^{14}$ Las pensiones del personal militar en retiro son generosas e incluyen su traspaso a las hijas solteras cuando fallece el beneficiario original. En los últimos años se redujeron parcialmente los privilegios de que disfrutaban los militares.
}

introducción del Plan Real, las prestaciones se reajustaron en proporciones superiores a la inflación corriente y se tradujeron en un aumento de su valor real medio. En promedio, el índice de la seguridad social fue ascendente hasta 1998 y se detuvo en 1999 debido al aumento de la inflación, para recuperar posteriormente su tendencia al alza como resultado de la política de reajustes reales del salario mínimo aplicada en el bienio 2000-2001 (gráfico 2). ${ }^{15}$

\footnotetext{
${ }^{15}$ El índice de seguridad social se calculó deflactando el incremento nominal de las prestaciones de seguridad social por el índice nacional de precios al consumidor en su concepto amplio (IPCA). Las prestaciones de seguridad social han aumentado, en general, en línea con los ajustes en los salarios mínimos, si bien con algunas diferencias en diversos años. En los casos en que las remuneraciones básicas se reajustaron por un factor distinto del que se aplicó a las prestaciones superiores a este mínimo, el índice se ponderó por el factor multiplicador (el total de prestaciones multiplicado por el valor mínimo) respecto del gasto total incluidas las prestaciones. El índice nos permitiría deducir la posible evolución del gasto en caso de que la cantidad de prestaciones permaneciera constante.
} 


\begin{tabular}{|c|c|c|c|}
\hline & $\begin{array}{c}\text { En porcentajes del salario mínimo legal, } \\
\text { en fecha de diciembre del } 2002\end{array}$ & \multicolumn{2}{|c|}{ Crecimiento medio anual $(\%)$} \\
\hline Total prestaciones & 164 & 4,2 & 3,5 \\
\hline Seguridad social & 172 & 3,7 & 3,4 \\
\hline Pensiones & 187 & 4,1 & 2,9 \\
\hline Por edad de jubilación & 113 & 1,9 & 3,4 \\
\hline Por años de servicio & 360 & 11,5 & 2,2 \\
\hline Por invalidez & 135 & 1,0 & 2,5 \\
\hline Asignaciones & 130 & 3,8 & 3,0 \\
\hline Otros & 224 & $-3,0$ & 12,6 \\
\hline Servicios de apoyo & 114 & 7,3 & 4,5 \\
\hline
\end{tabular}

Fuente: Ministerio de Previsión y Asistencia Social (varios años).

GRÁFICO 2

\section{Brasil: Índice de las prestaciones de seguridad sociala \\ (Base: junio $1994=100$ )}

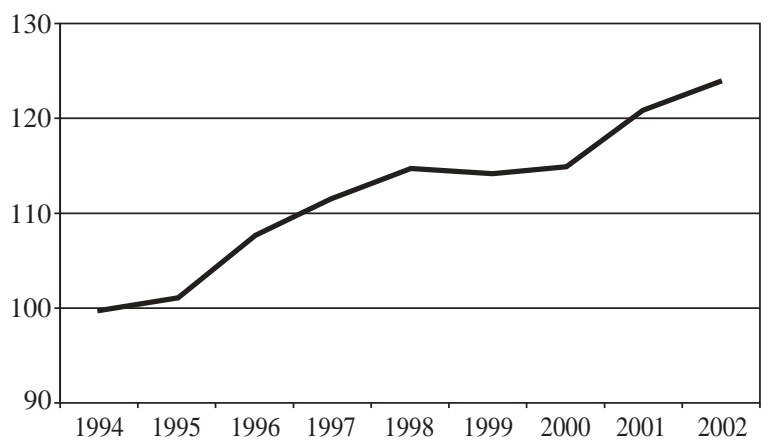

Fuente: Seguridad social y estimaciones de los autores.

a Deflactado por el Índice Nacional de Precios al Consumidor Ampliado (IPCA).

En los primeros años del Plan Real también aumentaron las prestaciones de seguridad social, encabezadas por las pensiones de jubilación basadas en los años de servicio, que eran más onerosas que las demás (cuadro 5). La jubilación por años de servicio que contempla la Constitución de Brasil permite que hombres y mujeres jubilen al cabo de 35 y 30 años de contribuciones, respectivamente, lo que puede reducir mucho la edad de jubilación. Entre 1995 y 1998, las jubilaciones por este concepto subieron a una tasa media anual de $11,5 \%$, mientras que las demás pensiones se elevaron 4,2\% (cuadro 5). Esta situación ha cambiado en los últimos años con la aprobación de la reforma de la seguridad social y el consiguiente descen- so de las solicitudes de jubilación. Finalmente, el número de beneficiarios del sistema de seguridad social aumentó a tasas superiores al crecimiento del PIB, con lo cual se produjo un incremento de la relación entre los gastos en seguridad social y el PIB. En parte esto se relaciona con el aumento del componente asistencial del bienestar social, que abarca a las personas que perciben un salario mínimo sin haber cotizado antes en el sistema de seguridad social.

\section{d) Otros gastos corrientes y de capital}

El principal incremento por este concepto se produjo en el bienio 1997-1998 (cuadro 3). En cambio, en el período 1999-2000, tras la firma del acuerdo de derecho de giro (stand-by) con el FMI a fines de 1998, este rubro se redujo apreciablemente. ${ }^{16}$ Sin embargo, entre el 2001 y 2002 se elevó nuevamente, reflejando en parte su creciente rigidez, ya que algunos organismos del sector público incrementaron los gastos comprometidos a fin de proteger sus recursos. La distribución de la responsabilidad por la creciente rigidez de estos gastos entre el poder ejecutivo y el legislativo es motivo de controversia. ${ }^{17}$

\footnotetext{
${ }^{16}$ En 1999, los “otros gastos corrientes y de capital", excluido el Fondo de Protección del Trabajador, cayeron 11\% en valores nominales. A comienzos de ese año esta partida se consideró imposible de recortar, pese al incremento observado desde 1994. La contracción que experimentó en 1999 sugiere que en los años anteriores los gastos por este concepto pueden haber sido inferiores.

${ }^{17}$ Pese a que la mayor parte de la responsabilidad por la creciente rigidez de "otros gastos corrientes y de capital" es atribuible al poder ejecutivo, en algunos años tal rigidez obedeció a la existencia de mayores compromisos debido a iniciativas de la legislatura como el Fondo de lucha contra la pobreza.
} 
CUADRO 6

Brasil: Crecimiento real del gasto no financiero del gobierno federal ${ }^{\mathrm{a}}$ (Promedio, en porcentajes)

\begin{tabular}{lccc}
\hline & $1994-1998$ & $1998-2002$ & $1994-2002$ \\
\hline Gasto no financiero & 7,0 & 4,6 & 5,8 \\
Gastos de personal & 2,0 & 4,2 & 3,1 \\
Prestaciones de seguridad social & 7,4 & 5,0 & 6,2 \\
Transferencias a estados yunicipios & 6,6 & 11,0 & 8,8 \\
Gastos de capital y otros costos & 12,3 & 0,7 & 6,3 \\
Partida pro memoria & & & 2,1 \\
Crecimiento real del PIB & 2,6 & 2,1 & 2,1 \\
\hline
\end{tabular}

Fuente: Secretaría de Política Económica del Ministerio de Hacienda.

a Deflactor implícito del producto interno bruto (PIB).

b Incluye el balance primario del Banco Central del Brasil.

La proporción de gastos no discrecionales en “otros gastos corrientes y de capital" aumentó de manera significativa, de $20 \%$ en 1999 a $60 \%$ en el 2002, incluyendo los gastos por concepto de salud, seguro de desempleo y fondo para combatir la pobreza. La mayor parte de los compromisos son relativamente nuevos y corresponden a disposiciones legales o constitucionales aprobadas en los últimos años. La existencia de esta rigidez en el gasto reduce el margen de maniobra de las autoridades para efectuar ajustes fiscales de corto plazo.

En síntesis, el total de gastos no financieros, incluidas las transferencias a los estados y municipios y el déficit del Banco Central de Brasil, aumentó 7,0\% al año en términos reales durante el primer gobierno de Cardoso y 4,6\% en el segundo. En el mismo período, el crecimiento del gasto fue muy superior al crecimiento del PIB real (el cuadro $6 \mathrm{y}$ el gráfico 3 muestran el gasto deflactado por el deflactor implícito del PIB).

\section{Los estados y los municipios}

Entre 1994 y 1998 los balances primarios de los estados y de los municipios se fueron deteriorando paulatinamente, para comenzar a mejorar a partir de 1998, particularmente en el caso de los estados (cuadros $1 \mathrm{y}$ 2). Los balances primarios estaduales y municipales exhibieron una mejora apreciable, en la que influyeron dos factores: las restricciones sobre sus presupuestos establecidas en los acuerdos bilaterales que suscribieron con el gobierno federal para refinanciar su deuda, y las disposiciones de la Ley de responsabilidad fiscal. Además, sus finanzas se vieron favorecidas por
GRÁFICO 3

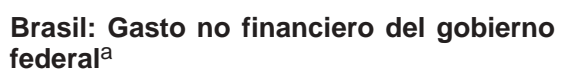

Brasil: Gasto no financiero del gobierno federala

(En miles de millones de reales del 2002)

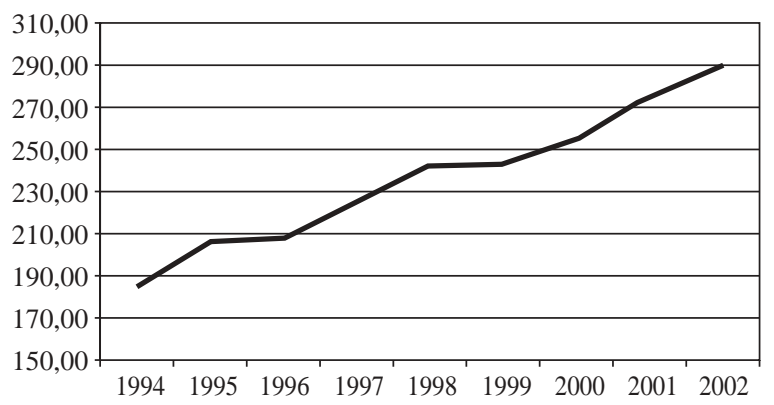

Fuente: Tesorería Nacional, Ministerio de Hacienda.

a Gastos corregidos por el deflactor implítico del PIB.

mayores recaudaciones de impuestos sobre algunos productos y servicios que subieron mucho de precio y que representaban una elevada proporción de sus ingresos, como el petróleo, las telecomunicaciones y la energía eléctrica.

Los esfuerzos por regular las finanzas estaduales y municipales comenzaron en 1993, cuando Cardoso aún era Ministro de Hacienda, al término del gobierno de Collor. El 17 de marzo de 1993 se aprobó una reforma al inciso $4^{\circ}$ del artículo 167 de la Constitución, que autorizaba a los estados a entregar en garantía sus propios ingresos y las transferencias del gobierno federal en los acuerdos de renegociación de la deuda que suscribieran con el gobierno federal. Esta reforma constitucional fue decisiva para el éxito de los acuerdos 
bilaterales sobre la deuda e hizo posible que todos los juicios entablados posteriormente por los estados fueran rechazados en la Corte Suprema. El 5 de noviembre de 1993 se promulgó la Ley 8.727, que permitía al gobierno federal refinanciar deudas estaduales con cinco bancos federales, a condición de que los estados pagaran una suma equivalente al menos a un $11 \%$ de sus ingresos y permitieran retener las transferencias del gobierno federal en caso de no pago. Los primeros acuerdos bilaterales sobre la deuda suscritos con arreglo a esta ley se firmaron en 1994. El 30 de noviembre de 1995, el Consejo Monetario Nacional aprobó el voto $162 / 95$ en virtud del cual por primera vez se condicionaba el refinanciamiento de la deuda de los estados a que asumieran compromisos fiscales. Estas tres medidas abrieron camino a la promulgación de la Ley 9.496, de 1997, que permitía refinanciar el saldo de la deuda garantizada de los estados. ${ }^{18}$ De acuerdo con la ley de 1997, los acuerdos bilaterales suscritos por el gobierno federal y los estados y municipios contemplaban pagos mensuales mínimos de $13 \%$ a $15 \%$ de sus ingresos (con un máximo de 30\%) durante 30 años, y tasas de interés real de $6 \%$ al año. El refinanciamiento de las deudas se garantizó mediante transferencias del gobierno federal y los ingresos del Impuesto sobre la Circulación de Mercaderías y de Servicios (el IvA estadual), que efectivamente impidieron que los estados dejaran de pagar sus obligaciones con el gobierno federal, puesto que dicho incumplimiento bloqueaba las transferencias y permitía que el Fisco se apropiara directamente de las entradas que percibieran los estados por concepto del ICMS. Estos acuerdos bilaterales indujeron a los estados y a los municipios a modificar sus respectivos sistemas fiscales de modo que generaran excedentes primarios para cumplir con sus obligaciones financieras.

Además de los acuerdos bilaterales, el otro hito institucional fue la promulgación de la Ley de responsabilidad fiscal, en el 2000. Entre otras cosas, la ley fijaba máximos a la nómina de pago del sector público de acuerdo con los ingresos del gobierno y prohibía el refinanciamiento de las deudas estaduales y municipales por el gobierno federal, poniendo fin al peligro que significaba que el sector privado otorgara

\footnotetext{
${ }^{18}$ En lo que respecta a los estados, el primer acuerdo bilateral que se celebró con arreglo a la Ley 9.496 se firmó en mayo de 1997 y el último en octubre de 1999. En el caso de los municipios, el primer acuerdo se suscribió en julio de 1999 y el último en mayo del 2000 .
}

préstamos a los gobiernos estaduales y municipales en la esperanza de que, a la larga, ellos serían pagados por el Tesoro Nacional. Por primera vez, los estados y los municipios debieron enfrentar una dura restricción presupuestaria.

El ajuste fiscal de los estados y de los municipios también se vio favorecido por el incremento de los ingresos tributarios estaduales y por las transferencias del gobierno federal. A contar de 1998, aumentaron los ingresos del ICMS (el IVA de los estados), lo que indicaba que los gobernadores elegidos ese año habían mejorado la administración fiscal y el hecho que, en parte, los ingresos del ICMS se habían concentrado en sectores que encabezaron la reanudación del crecimiento, como las telecomunicaciones, o cuyos precios habían aumentado, como la gasolina y los derivados de petróleo en general. Entre 1998 y 2002, los ingresos del ICMS se elevaron de 6,7\% a 7,9\% del PIB. Al mismo tiempo, las transferencias a los estados y a los municipios aumentaron del $3,0 \%$ a $4,3 \%$ del PIB, tras las reformas introducidas en la legislación como resultado de las presiones de los gobernadores estaduales, en especial de la revisión de la ley Kandir. ${ }^{19}$ Debido a estos dos hechos, en el período 1999-2002 los ingresos de los estados y de los municipios se acrecentaron en 2,5\% del PIB, lo que en gran medida explica el mejoramiento de su balance primario.

\section{Las empresas públicas}

El balance primario de las empresas públicas también ha mejorado desde 1999 (cuadro 7). La mejora en el caso de las empresas federales se debió principalmente a los resultados de la empresa petrolera estatal (Petrobras) que en 1999 se vio favorecida por el alza de los precios internacionales del crudo. El traspaso de los precios del mercado internacional afectó los precios internos, pero influyó sólo en parte de los costos de Petrobras, ya que la mayoría de los productos de petróleo que comercializa dicha empresa deriva de la producción nacional. Los mejores resultados de

\footnotetext{
${ }^{19}$ La Ley Kandir fue negociada por el gobierno federal y los gobiernos estaduales antes de la devaluación de 1999, a fin de proporcionar un incentivo tributario a los exportadores: los estados no aplicarían el ICMs sobre las exportaciones, a cambio del pago de una indemnización por el gobierno federal. Posteriormente, los estados sostuvieron que la indemnización se había calculado erradamente y lograron que el gobierno federal se comprometiera a realizar sustanciales transferencias complementarias a lo largo de varios años.
} 
CUADRO 7

Brasil: Balance primario de las empresas públicas ${\text { (En porcentajes del } P I B)^{a}}^{a}$

\begin{tabular}{|c|c|c|c|c|c|c|c|c|c|}
\hline & 1994 & 1995 & 1996 & 1997 & 1998 & 1999 & 2000 & 2001 & 2002 \\
\hline Total balance & 1,2 & $-0,1$ & 0,1 & 0,1 & $-0,4$ & 0,7 & 1,1 & 0,9 & 0,7 \\
\hline Empresas federales & 1,6 & 0,4 & 0,3 & 0,3 & $-0,2$ & 0,7 & 0,9 & 0,6 & 0,5 \\
\hline Ingresos & 9,0 & 8,8 & 8,7 & 8,2 & 7,0 & 6,8 & 8,1 & 8,4 & $\ldots$ \\
\hline Gastos no financieros & 9,0 & 8,5 & 8,3 & 7,9 & 7,2 & 6,7 & 7,5 & 8,5 & $\ldots$ \\
\hline Salarios & 1,6 & 1,4 & 1,4 & 1,1 & 0,9 & 0,6 & 0,6 & 0,5 & $\ldots$ \\
\hline Otros gastos & 5,8 & 5,6 & 5,0 & 4,9 & 4,5 & 4,8 & 5,6 & 6,4 & $\ldots$ \\
\hline Otros gastos de capital & 0,1 & 0,2 & 0,4 & 0,4 & 0,5 & 0,6 & 0,5 & 0,5 & $\ldots$ \\
\hline Ajustes & 1,7 & 0,2 & $-0,2$ & 0,0 & $-0,1$ & 0,6 & 0,3 & 0,7 & $\ldots$ \\
\hline Empresas estaduales y municipales & 0,0 & $-0,5$ & $-0,2$ & $-0,2$ & $-0,1$ & 0,0 & 0,1 & 0,3 & 0,3 \\
\hline Empresas estaduales & $\ldots$ & $-0,5$ & $-0,2$ & $-0,2$ & $-0,1$ & 0,0 & 0,1 & 0,3 & 0,3 \\
\hline Empresas municipales & $\ldots$ & 0,0 & 0,0 & 0,0 & 0,0 & 0,0 & 0,0 & 0,0 & 0,0 \\
\hline
\end{tabular}

Fuente: Ministerio de Planificación y Banco Central del Brasil.

a El signo menos indica déficit.

Petrobras también permitieron cierto margen para que las empresas públicas en general aumentaran sus inversiones sin afectar sus necesidades de financiamiento. ${ }^{20}$

El mejoramiento del balance primario de las empresas estaduales y municipales se debió a la privati- zación de las empresas que trabajaban a pérdida y a los cambios introducidos en la gestión de las empresas que siguieron perteneciendo al Estado. En general, las autoridades nombraron administradores a personas resueltas a ser eficientes y que debieron actuar en un medio mucho más competitivo.

\section{IV}

\section{Fuentes de ingreso transitorias}

Compensar la pérdida gradual de ingresos transitorios será tarea difícil. El ajuste deberá combinar recortes de gastos, la eliminación gradual de los ingresos transitorios y posiblemente la transformación de algunos ingresos transitorios en permanentes.

A fines de 1993 se aprobó el impuesto provisional sobre las transacciones financieras, que fue abolido al año siguiente. En esa oportunidad, el gobierno introdujo ingresos de carácter "transitorio" o que se

\footnotetext{
${ }^{20}$ En el período 2001-2002 el excedente primario agregado de las empresas federales, incluida la central hidroeléctrica de Itaipú, alcanzó un promedio cercano al 0,5\% del PIB. Este excedente primario se descompone en un excedente de $0,4 \%$ del PIB en el caso de Petrobras y $0,2 \%$ del PIB en el de Itaipú, y en un déficit primario de $0,1 \%$ en el caso del grupo Eletrobras, que se explica por la baja de los ingresos debido a la crisis energética, unida al aumento de la inversión. El resultado básico de las demás empresas federales fue prácticamente nulo.
}

percibían por una sola vez, los que en los años siguientes pasaron a ser práctica común. ${ }^{21}$ En definitiva, los ingresos extraordinarios alcanzaron su punto máximo de 3\% del PIB en 1999 y en el período 2000-2002 siguieron aportando un promedio de $2,5 \%$ del PIB (cuadro 8).

Pese a que el impuesto provisional sobre las transacciones financieras (IPMF) fue abolido en 1994, en 1997 se restableció el mismo impuesto con el nombre de contribución provisional sobre el movimiento financiero (CPMF), que se prorrogó en los años siguientes. En

\footnotetext{
${ }^{21}$ Los ingresos transitorios corresponden a una fuente de ajuste que no se prolonga en el tiempo. Hasta cierto punto, la definición de lo que constituyen "ingresos transitorios" es algo arbitrario. Para nosotros, son aquellos ingresos estrictamente transitorios (en vigor sólo durante un año) o que tenderían a desaparecer a menos que se modificara la legislación que les dio origen.
} 
CUADRO 8

Brasil: Ingresos transitorios del gobierno federal (En porcentajes del PIB)

\begin{tabular}{|c|c|c|c|c|c|c|c|c|}
\hline & 1995 & 1996 & 1997 & 1998 & 1999 & 2000 & 2001 & 2002 \\
\hline Total & 0,5 & 0,5 & 1,4 & 2,8 & 3,2 & 2,3 & 2,3 & 2,9 \\
\hline IPMF/CPMF ${ }^{\mathrm{a}}$ & 0,0 & 0,0 & 0,8 & 0,9 & 0,8 & 1,3 & 1,5 & 1,5 \\
\hline Concesiones & 0,0 & 0,0 & 0,2 & 1,0 & 0,9 & 0,5 & 0,4 & 0,3 \\
\hline Impuesto adicional a la renta de las personas & 0,0 & 0,0 & 0,0 & 0,1 & 0,1 & 0,1 & 0,1 & 0,1 \\
\hline Impuesto adicional a la renta de valores & 0,0 & 0,0 & 0,0 & 0,3 & 0,0 & 0,0 & 0,0 & 0,0 \\
\hline Impuesto adicional a la renta por remesas externas & 0,0 & 0,0 & 0,0 & 0,0 & 0,2 & 0,0 & 0,0 & 0,0 \\
\hline Término de la rebaja de la COFINS & 0,0 & 0,0 & 0,0 & 0,0 & 0,3 & 0,3 & 0,3 & 0,3 \\
\hline Fondo de estabilidad fiscal & 0,5 & 0,5 & 0,4 & 0,3 & 0,3 & 0,0 & 0,0 & 0,0 \\
\hline Recaudación de impuestos atrasados & 0,0 & 0,0 & 0,0 & 0,2 & 0,6 & 0,1 & 0,0 & 0,7 \\
\hline
\end{tabular}

Fuente: Estimaciones de los autores.

a IPMF/CPMF = Impuesto provisorio sobre el movimiento financiero/contribución provisoria sobre el movimiento financiero.

1994 se creó el Fondo social de emergencia (FSE), mecanismo en virtud del cual el gobierno federal retuvo parte de las transferencias a los estados y municipios durante dos años (1994 y 1995). Posteriormente, el fondo fue renovado en 1996 por un año y medio, con iguales características y con el nuevo nombre de Fondo de estabilización fiscal (FEF). A mediados de 1997, el FEF fue renovado nuevamente por otros dos años y medio, aunque sujeto a un incremento gradual de los pagos por transferencias a los municipios, y sólo fue suprimido en diciembre de 1999.
Además, se generaron ingresos importantes mediante la licitación de las concesiones de telefonía celular y la privatización de la empresa estatal de telecomunicaciones (Telebras). Parte de los ingresos obtenidos de la privatización de Telebras (40\%) se consideraron ingresos tributarios al establecer el monto del déficit del sector público, a diferencia de otras privatizaciones, que no influyeron en tal déficit. Además, a raíz de la condonación de los intereses por el pago atrasado, se pudo cobrar impuestos en mora. ${ }^{22}$

\section{$\mathrm{V}$}

\section{El crecimiento de la deuda pública y las obligaciones ocultas}

La relación entre la deuda pública y el PIB, incluida la base monetaria, había caído de un máximo de $56 \%$ en 1984 a $30 \%$ en 1994, debido a la combinación de un señoreaje elevado, un déficit operativo bajo en la primera mitad del decenio de 1990, una corrección del valor nominal de la deuda en proporción inferior a la inflación y un crecimiento económico acumulado de 32\% en el período 1985-1994. Entre 1994 y 1998, esa relación tuvo un alza marcada, debido principalmente al persistente déficit público. Hacia fines de 1998, el gobierno agotó sus opciones de financiamiento del déficit (cuadro 9): el señoreaje era pequeño, los grupos políticos rechazaban unánimemente una vuelta a la inflación, el elevado nivel de la deuda externa había conducido al colapso del tipo de cambio, el refinanciamiento de la deuda interna se tornó cada vez más

\footnotetext{
${ }^{22}$ También se aplicaron otras medidas: un recargo al impuesto sobre los ingresos personales en los tramos superiores a partir de 1998; excepcionalmente, en 1998, un doble impuesto sobre los ingresos de los instrumentos financieros; un recargo al impuesto sobre los ingresos por las utilidades obtenidas en algunas operaciones a raíz de la devaluación de la moneda; la suspensión transitoria a partir de 1999 de la deducción de parte de la contribución para el financiamiento de la seguridad social, inicialmente autorizada para el pago del impuesto sobre los ingresos de las empresas; el pago de impuestos atrasados por los fondos de pensiones en el 2002, y otras medidas.
} 
CUADRO 9

Brasil: Deuda pública neta

(En porcentajes del PIB)

\begin{tabular}{|c|c|c|c|c|c|c|c|c|c|}
\hline & 1994 & 1995 & 1996 & 1997 & 1998 & 1999 & 2000 & 2001 & 2002 \\
\hline Total deuda ${ }^{\mathrm{a}}$ & 30,0 & 30,6 & 33,3 & 34,3 & 41,7 & 48,7 & 48,8 & 52,6 & 55,5 \\
\hline Gobierno federal & 13,0 & 13,3 & 16,0 & 18,6 & 24,9 & 29,8 & 30,6 & 32,7 & 35,3 \\
\hline Estados y municipios & 9,9 & 10,7 & 11,5 & 12,9 & 14,2 & 16,2 & 16,0 & 18,3 & 18,5 \\
\hline Empresas del sector público & 7,1 & 6,6 & 5,8 & 2,8 & 2,6 & 2,7 & 2,2 & 1,6 & 1,7 \\
\hline Deuda interna & 21,5 & 25,1 & 29,4 & 30,0 & 35,5 & 38,4 & 39,2 & 42,2 & 41,2 \\
\hline Base monetaria & 3,6 & 3,1 & 2,4 & 3,6 & 4,2 & 4,6 & 4,2 & 4,2 & 4,6 \\
\hline Deuda actualizada ${ }^{b}$ & 11,7 & 15,6 & 21,4 & 28,1 & 34,5 & 38,6 & 41,8 & 48,1 & 37,8 \\
\hline Créditos del Banco Central de Brasil ${ }^{\mathrm{c}}$ & $-4,6$ & $-5,3$ & $-8,5$ & $-7,8$ & $-5,6$ & $-4,4$ & $-3,7$ & $-3,2$ & $-2,6$ \\
\hline \multicolumn{10}{|l|}{ Refinanciamiento de los estados y } \\
\hline municipios y PROES & 0,0 & 0,0 & 0,0 & $-5,4$ & $-9,3$ & $-12,4$ & $-13,4$ & $-13,9$ & $-13,7$ \\
\hline Fondo de Protección del Trabajador (FAT) & $-2,0$ & $-2,5$ & $-2,5$ & $-2,6$ & $-3,5$ & $-3,9$ & $-4,4$ & $-4,9$ & $-4,8$ \\
\hline Otros & $-2,0$ & $-1,1$ & 1,6 & 0,8 & 0,5 & $-0,6$ & $-1,3$ & $-5,8$ & 1,6 \\
\hline Refinanciamiento de estados y municipios & 0,0 & 0,0 & 0,0 & 5,4 & 9,3 & 12,4 & 13,4 & 13,9 & 13,7 \\
\hline Deuda convertida & 4,8 & 5,6 & 6,2 & 4,3 & 2,4 & 1,3 & 0,2 & 0,2 & 0,1 \\
\hline Otros & 4,8 & 4,8 & 4,9 & 2,7 & 1,8 & 1,6 & 1,5 & 3,2 & 3,3 \\
\hline Empresas del sector público & 5,2 & 4,9 & 3,9 & 0,9 & 1,2 & 1,2 & 0,9 & 0,4 & 1,2 \\
\hline Deuda pública externa & 8,5 & 5,5 & 3,9 & 4,3 & 6,2 & 10,3 & 9,6 & 10,4 & 14,3 \\
\hline Gobierno federal & 6,3 & 3,5 & 1,6 & 1,9 & 4,1 & 7,9 & 7,4 & 8,2 & 12,4 \\
\hline Estados y municipios & 0,3 & 0,3 & 0,4 & 0,5 & 0,7 & 0,9 & 0,9 & 1,0 & 1,4 \\
\hline Empresas públicas & 1,9 & 1,7 & 1,9 & 1,9 & 1,4 & 1,5 & 1,3 & 1,2 & 0,5 \\
\hline \multicolumn{10}{|l|}{ Partidas pro memoria } \\
\hline Deuda fiscal ${ }^{\mathrm{d}}$ & 30,0 & 30,6 & 31,4 & 34,2 & 40,6 & 40,7 & 40,9 & 40,8 & 36,1 \\
\hline Ajuste del balance (acciones) & 0,0 & 0,0 & 1,9 & 0,1 & 1,1 & 8,0 & 7,9 & 11,8 & 19,4 \\
\hline Privatizaciones & 0,0 & 0,0 & $-0,1$ & $-2,0$ & $-3,3$ & $-3,8$ & $-5,2$ & $-4,8$ & $-4,0$ \\
\hline Otros & 0,0 & 0,0 & 2,0 & 2,1 & 4,4 & 11,8 & 13,1 & 16,6 & 23,4 \\
\hline Ajuste de la deuda interna & 0,0 & 0,0 & 0,0 & 0,0 & 0,4 & 4,2 & 4,6 & 6,0 & 9,6 \\
\hline Deuda en dólares & 9,5 & 6,3 & 5,9 & 8,7 & 13,5 & 19,6 & 19,6 & 25,0 & 28,9 \\
\hline (porcentaje de la deuda total) & 31,7 & 20,6 & 17,7 & 25,4 & 32,4 & 40,2 & 40,2 & 47,5 & 52,1 \\
\hline
\end{tabular}

Fuente: Banco Central de Brasil.

a Incluye base monetaria y ajustes del balance.

b A partir del 2002, incluye créditos recíprocos.

c Préstamos del Banco Central de Brasil a instituciones financieras.

d Deuda proveniente de la emisión de valores públicos únicamente.

oneroso y las privatizaciones llegaban a su fin. En estas circunstancias, el gobierno inició el proceso de ajuste fiscal con arreglo a un programa apoyado por el FMI. ${ }^{23}$

En el período 1995-1998, la deuda pública total subió, principalmente por la emisión de bonos del gobierno federal y en parte por la transferencia de las deudas de los estados al gobierno federal. Este aumento de las obligaciones del gobierno federal no afectó de inmediato la deuda pública neta, pero no tuvo carácter

23 Véase en Pastore (1995), Tanner (1995) y Rocha (1997) una reseña de las raíces históricas de la deuda pública de Brasil. neutro, ya que los activos y pasivos en juego involucraron diversos costos y vencimientos (Werneck y Bevilaqua, 1998). Como consecuencia, entre 1994 y 1998 la deuda pública total, incluida la base monetaria, se elevó en un $12 \%$ del PIB, mientras que la deuda interna en valores públicos aumentó en 23\% del PIB en el mismo período.

Pese al ajuste del balance primario, la deuda pública total se acrecentó después de 1999 debido al impacto de la devaluación en la deuda pública externa y en la deuda pública interna, cuya participación en la deuda global aumentó marcadamente en los dos años 
anteriores. En el momento de la devaluación, la deuda pública en dólares alcanzaba a 14\% del PIB (o 30\% de la deuda pública total). Entre el 2000 y 2002, al caer marcadamente el valor de la moneda brasileña respecto del dólar, la deuda pública en dólares se incrementó sustancialmente, llegando a 29\% del PIB (o 50\% de la deuda pública total) a fines del 2002 (cuadro 9).

Un elemento fundamental de la evolución de la deuda pública desde mediados del decenio de 1990 fueron los "ajustes del balance" (Passini, 2000; Kawall, Costa y Gomes, 2000), provenientes de tres factores, a saber:

- el reconocimiento de deudas antiguas que habían afectado la demanda agregada en el pasado, pero que no se habían registrado de manera correspondiente en las estadísticas fiscales de la época (los llamados “esqueletos");
- las fluctuaciones de valor de la deuda debidas a oscilaciones del tipo de cambio; y

- los ingresos de las privatizaciones, que se utilizaron para reducir el monto de la deuda pública. Hasta 1995, las estadísticas fiscales no tenían claramente en cuenta estos factores. En conjunto, entre 1999 y 2002 la suma de los dos primeros efectos representó un aumento acumulado de la deuda pública equivalente a $19 \%$ del PIB, mientras que las privatizaciones contribuyeron a reducir la deuda en un $1 \%$ del PIB, traduciéndose en un incremento neto de alrededor de $18 \%$ del PIB. Esto explica parcialmente por qué Brasil, pese a haber cumplido con sus obligaciones fiscales e incluso sobrepasado las metas establecidas en el acuerdo que suscribió con el FMI, vio aumentar la relación entre la deuda pública y el PIB respecto de su nivel anterior a la devaluación de $1999 .{ }^{24}$

\section{VI}

\section{La postura fiscal de las autoridades}

Antes de 1998, las autoridades no controlaron las cuentas del sector público con la misma severidad con que lo hicieron después de 1999, en medio de una crisis externa y fiscal. ${ }^{25}$ Durante el primer gobierno de Cardoso, el gasto controlado directamente por el gobierno y no sujeto a restricciones legales o constitucionales aumentó fuertemente y hasta 1998 las propuestas de que se adoptaran metas fiscales carecieron de apoyo.

\footnotetext{
${ }^{24}$ El tipo de cambio tiene un doble efecto en la deuda a través de un ajuste del balance: aumenta la deuda pública externa y eleva el valor de la deuda interna expresada en dólares. Este efecto fue particularmente pronunciado en 1999, 2000 y 2001, y explica los saltos en la relación entre la deuda y el PIB, pese a los buenos resultados del balance primario observados después de 1998.

${ }^{25}$ Un juicio más generoso de la posición oficial anterior a 1999 reconocería que en el período 1995-1998 el gobierno tenía un ambicioso programa de reformas, que incluía la aprobación de reformas constitucionales, algunas de las cuales fueron importantes para el ajuste fiscal posterior (como la reforma del sistema de seguridad social, que tuvo una prolongada tramitación en el Congreso). Como resultado, centrarse en las reformas habría conducido a una relajación de las corrientes fiscales de corto plazo, al amparo de un ambiente externo favorable que financió el creciente déficit de cuenta corriente hasta 1999. La conclusión de que, en un ambiente como ese, en el período 1995-1998 se hubiera podido imponer el mismo tipo de restricciones presupuestarias que el observado en 1999-2002 es una afirmación contrafáctica difícil de sostener.
}

Como había ocurrido antes por más de dos decenios, Brasil atravesó por una situación de restricciones presupuestarias débiles (Kornai, 1986, p. 4). Cuando las restricciones presupuestarias son débiles, la tendencia natural es que el ajuste tenga lugar por medio de una inflación más alta, cuando la política monetaria es floja o por medio de una deuda pública mayor, cuando una política monetaria es rigurosa impide que los desequilibrios fiscales afecten los precios a corto plazo, sólo para agravar los desequilibrios fiscales futuros con el aumento de la carga de intereses (Sargent y Wallace, 1981).

La crisis de 1998-1999 cambió esta situación, dándoles la razón a quienes en el gobierno de Cardoso propiciaban la aplicación de una política fiscal más severa. La verdad es que el ajuste fiscal fue impuesto por las circunstancias ya que, de no haberse realizado, Brasil indudablemente se habría encaminado hacia una moratoria de la deuda pública interna. En realidad, Cardoso — que estaba convencido de que para obtener el apoyo del FMI había que aumentar los impuestos y reducir el gasto - dio el respaldo necesario a la adopción de las medidas de austeridad fiscal requeridas y encabezó las negociaciones con el Congreso Nacional para que se aprobara la legislación pertinente. En estas circunstancias, la relativa pasividad fiscal del primer 
gobierno de Cardoso cedió paso a una posición activa en pro de un esfuerzo fiscal orientado a frenar el aumento de la deuda pública.

$\mathrm{Al}$ respecto, es preciso hacer dos salvedades. Primero, algunos han sugerido que más que un cambio de actitud de las autoridades, simplemente hubo mayor preocupación por financiar el gasto en forma adecuada, ya que nunca se había reducido la relación en- tre el gasto público y el PIB. Segundo, el ajuste se basó en parte en ingresos transitorios tales como la CPMF y en las entradas adicionales que percibió Petrobras por el alza de los precios de los combustibles. Esto no significa restar mérito al esfuerzo fiscal realizado en el período 1999-2002, pero pone de relieve la necesidad de preservar y mejorar el ajuste en los años siguientes.

\section{VII}

\section{El futuro de la sustentabilidad fiscal}

La actitud del gobierno frente a la política fiscal experimentó un vuelco notable con la crisis externa y fiscal de 1998-1999. Como resultado, se fortalecieron los argumentos de quienes en el gobierno de Cardoso propiciaban la aplicación de políticas fiscales más austeras, los que pudieron inclinar la balanza hacia la adopción de políticas más severas que hasta 1998 habían recibido escaso apoyo. Sólo diez días antes de las elecciones de 1998, el presidente Cardoso pronunció un discurso que puso de manifiesto la austeridad que se venía encima. Hizo hincapié en la necesidad de "asegurar que el Estado viva de acuerdo con sus medios" y genere excedentes de balance primario "suficientes para impedir que la deuda pública aumente a un ritmo superior al PIB, manteniendo la estabilidad de la relación entre ambos en el tiempo". ${ }^{26}$ Pese a que se trató de una afirmación más bien trivial, era notable el contraste entre lo expresado por el presidente y la evolución de la deuda pública en los últimos años. Incluso seis meses antes no habría podido afirmarse algo tan obvio. Las condiciones políticas para la adopción de una norma fiscal más austera se originaron en la extraordinaria crisis externa, durante la cual la salida de reservas en divisas alcanzó a mil millones de dólares al día, hecho vinculado no sólo con un tipo de cambio sobrevalorado sino también con una situación fiscal insostenible.

La situación que heredó el presidente Cardoso a mediados del decenio de 1990 correspondía a un problema profundamente arraigado: desde 1954 se habían alternado políticas populistas expansionistas con breves intervalos de políticas reformistas conservadoras. ${ }^{27} \mathrm{La}$

${ }^{26}$ Véase Jornal do Brasil (1998).

27 Véase Rabello de Castro y Ronci (1991). crisis de 1998-1999 creó un clima político propicio para la adopción de medidas encaminadas a resolver los profundos desequilibrios fiscales de carácter estructural $\mathrm{y}$, lo que es más importante, para hacer de la austeridad una norma de administración pública, en un auténtico vuelco respecto de la antigua prodigalidad fiscal. El que perdure esta nueva actitud de las autoridades sólo podrá comprobarse con el paso del tiempo. ${ }^{28}$

Sin embargo, el ajuste observado después de 1999 se basó en gran medida en el aumento de los ingresos, puesto que en valores reales el gasto público global no se vio mayormente afectado. El gasto no financiero real del gobierno federal, incluidas las transferencias a los estados y los municipios y el pequeño déficit del Banco Central, aumentaron sostenidamente en cada uno de los ocho años abarcados por los dos gobiernos de Cardoso.

Además, parece justificarse que Brasil —cuya credibilidad sigue estando debilitada tras años de hiperinflación reprimida, grandes déficit y creciente deuda pública- continuará registrando grandes excedentes primarios durante varios años, antes de reducirlos gradualmente sin afectar la evolución de la deuda del sector público.

Estos aspectos del ajuste fiscal efectuado por Cardoso ponen de relieve la necesidad de preservar en los próximos años la disciplina fiscal que costó tanto imponer. Para mejorar la calidad del ajuste será preciso compensar la eliminación gradual de los ingresos transitorios, transformando parte de ellos en ingresos permanentes y recortando el gasto público a través de todas las partidas presupuestarias. Además,

\footnotetext{
${ }^{28}$ Uno de los elementos importantes del mayor control fiscal fue la mejora de las estadísticas del sector público a partir de 1995.
} 
habrá que reducir los gastos no discrecionales a fin de permitir un mayor margen para ajustes fiscales de corto plazo.

Fundamental para que haya sustentabilidad fiscal es la reciente austeridad fiscal que han propiciado las autoridades y que debería transformarse en un elemento permanente de las instituciones fiscales. Una alternativa posible sería complementar la Ley de responsabilidad fiscal con una "ley de solvencia fiscal" que estableciera normas claras y permanentes para asegurarse de que la deuda pública sea sostenible a mediano plazo, ya sea fijando un máximo a las necesidades de financiamiento o un mínimo al excedente primario. ${ }^{29}$ La ley de solvencia fiscal ayudaría a aminorar los efec- tos fiscales de la fragmentación política, así como las presiones legítimas para conseguir que se eleve el gasto social en los próximos años. Además, podría contrapesarse mejor la relación entre el ajuste fiscal y el crecimiento económico de corto plazo por la vía de fortalecer la credibilidad y permitir tasas de interés más bajas. Sin embargo, el resultado de cualquier reforma legal a las instituciones fiscales brasileñas dependerá fundamentalmente de que tanto los que formulan las políticas como los políticos estén convencidos de que la sustentabilidad fiscal es un bien público valioso y una condición necesaria para el crecimiento. Sin este entendido, toda reforma de las instituciones fiscales será inevitablemente efímera.

APÉNDICE

\section{La sostenibilidad de la deuda pública, 1995-2002}

Pese a las reformas fiscales de Cardoso y al notable viraje hacia la austeridad que se produjo después de 1999, todo indica que la deuda pública no era sostenible en el período 1995-2002 ni en el período 1999-2002. En otras palabras, que la política fiscal no fue lo bastante severa como para detener el crecimiento de la deuda pública.

Para verificar la sostenibilidad fiscal del período comprendido entre enero de 1995 y diciembre del 2002 aplicamos la prueba elaborada por Wilcox (1989) y Luporini (2000). Dicha prueba consiste en comprobar si la deuda pública actualizada por el factor de descuento es estacionaria (de raíz unitaria). Si esa deuda fuese estacionaria (rechazo de la hipótesis de raíz unitaria), sería sostenible de acuerdo con la política fiscal aplicada en el período de la muestra.

El conjunto de datos está formado por las estadísticas mensuales de la deuda pública neta actualizada a su valor a

\footnotetext{
${ }^{29}$ Pese a que la Ley de responsabilidad fiscal y el refinanciamiento de las deudas estaduales y municipales introdujeron una fuerte restricción presupuestaria en el sistema fiscal de los estados y municipios, el presupuesto del gobierno federal no ha estado sometido a iguales restricciones. Las metas de excedente de balance primario del gobierno federal sólo se aplican al ejercicio presupuestario corriente y pueden revisarse al año siguiente: en principio, el gobierno federal no tiene una restricción presupuestaria clara y perdurable que le impida una reducción sustancial del excedente primario, lo que puede implicar un aumento de la relación deuda/PIB.
}

la par. La deuda nominal se dividió por el índice general de precios. Para calcular los factores de descuento reales se dividió la tasa de interés del Sistema Especial de Liquidación y Custodia (SELIC) por el índice general de precios. ${ }^{30}$ El gráfico A.1 muestra la deuda pública y la deuda pública actualizada, ambas expresadas en reales de diciembre del 2002.

El cuadro A.1 resume la comprobación del carácter estacionario de la deuda pública neta actualizada $t$ utilizando la prueba de Dickey-Fuller aumentada. ${ }^{31}$ La hipótesis de raíces unitarias no se rechaza respecto de todos los períodos de la muestra, lo que confirma que, pese a los esfuerzos realizados por el gobierno, en los períodos comprendidos entre enero de 1995 y diciembre del 2002 y enero de 1999 y diciembre del 2002, la política fiscal no fue lo suficientemente restrictiva como para que la deuda pública fuera sostenible.

(Traducido del inglés)

\footnotetext{
${ }^{30}$ Lo ideal sería utilizar la tasa de interés real descontados los impuestos. Sin embargo, es casi imposible estimar el rendimiento de los valores descontados los impuestos, puesto que las tasas de interés varían según el tenedor del valor y se dispone de escasa información respecto a su identidad.

${ }^{31}$ Verificamos los resultados de la prueba de Dickey-Fuller aumentada de acuerdo con la metodología descrita por Enders (1995).
} 
GRÁFICO A1

Brasil: Total deuda pública neta

(En miles de millones de reales de diciembre del 2002)

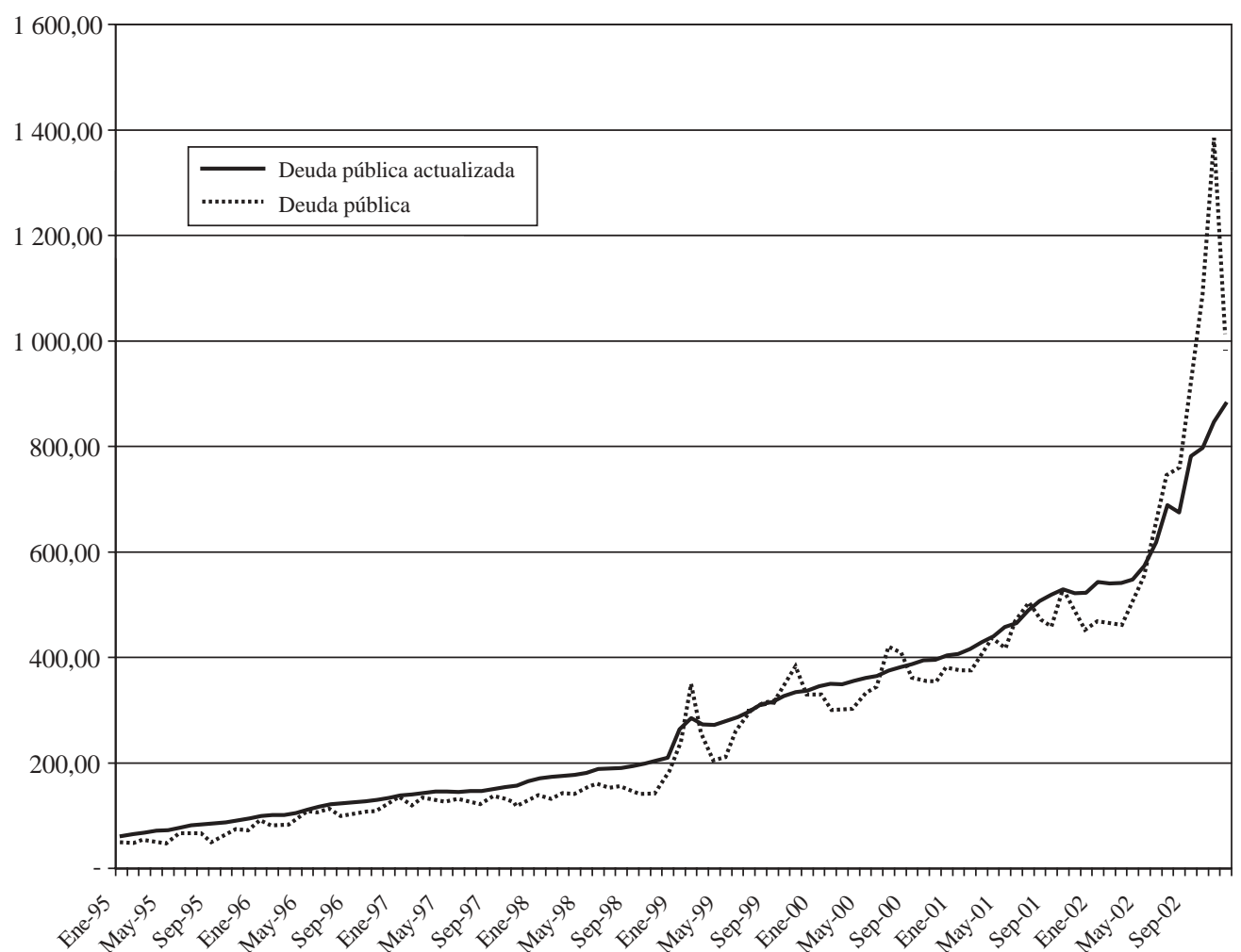

Fuente: Banco Central de Brasil.

CUADRO A.1

Brasil: Prueba de la estacionariedad de la deuda pública actualizada

Período de la muestra Enero 1995-diciembre 2002

Enero 1995-diciembre 1998

Enero 1999-diciembre 2002

Hipótesis nula de raíz unitaria

Prueba de Dickey-Fuller aumentada (Probabilidad)

Valores críticos de la prueba

$1 \%$ de significación

$5 \%$ de significación

$10 \%$ de significación

Número de rezagos

Número de observaciones

No rechazada a nivel de $10 \%$

0,17651

$(-0,9976)$

$-4,045236$

$-3,451959$

$-3,151440$

6

96
No rechazada a nivel de $10 \%$

$-3,048911$

$(0,1281)$

$-4,118444$

$-3,486509$

$-3,171541$
No rechazada a nivel de $10 \%$

$-1,880546$

$(0,6522)$

$-4,118444$

$-3,486509$

$-3,171541$

Fuente: Estimaciones de los autores. 


\section{Bibliografía}

Além, A.C. y F. Giambiagi (1999): Finanças publicas: teoria e pratica no Brasil, Rio de Janeiro, Editora Campus.

Banco Central del Brasil (2000): Relatorio Focus, Brasilia, 16 de octubre.

Barbosa, F., A. Salazar Brandão y C. de Faro (1989): Fiscal Reform and Stabilization: the Brazilian Experience, Rio de Janeiro, Fundación Getulio Vargas, agosto.

Enders, W. (1995): Applied Econometric Time Series, Nueva York, John Wiley and Sons.

Ferreira, A. y G. Tullio (2002): The Brazilian exchange rate crisis of January 1999, Journal of Latin American Studies, vol. 34, $\mathrm{N}^{\circ} 1$, Nueva York, Cambridge University Press.

Garcia, M.G.P. y T. Didier (2000): Taxa de juros, risco cambial e risco Brasil, documento presentado en el III Encontro da Economia da Região Sul, septiembre, Anpec Sul.

Giambiagi, F. (1997): Necessidades de financiamento do setor publico 1991/96: bases para a discussão do ajuste fiscal no Brasil, Pesquisa e planejamento econômico, vol. $27, \mathrm{~N}^{\circ} 1$, Rio de Janeiro, Instituto de Investigación Económica Aplicada (IPEA), abril.

Giambiagi, F. y M. Ronci (2004): Fiscal Policy and Debt Sustainability: Cardoso's Brazil, 1995-2002, IMF Working Paper WP/04/156, Washington, D.C., agosto.

Jornal do Brasil (1998): 24 de septiembre.

Kawall, C.L.F, R. Costa y T.G. Gomes (2000): A dívida publica e os esqueletos, Economic Update, Citibank, 29 de septiembre.

Kornai, J. (1986): The soft budget constraint, Kyklos, vol. 39, № 1 , Cambridge, Blackwell Publishing.

Luporini, V. (2000): Sustainability of the Brazilian fiscal policy and Central Bank independence, Revista brasileira de economia, vol. 54, No 2, Rio de Janeiro, Fundación Getulio Vargas, enero/ marzo.

Mendonça de Barros, J.R. y M.F. Almeida (1996): A reestruturação do sistema financeiro, Gazeta mercantil, 26 de agosto.

Ministerio de Previsión y Asistencia Social (varios años): Anuario estadístico da previdência social.

North, D.C. (1990): Institutions, Institutional Change and Economic Performance, Cambridge, Cambridge University Press.
Ornelas, W. y S. Vieira (1999): As novas regras da previdência social, Conjuntura econômica, vol. 53, No 11 , Rio de Janeiro, Fundación Getulio Vargas, noviembre.

Passini, S. (2000): Fiscal Skeletons in Brazil, Stanford, UBS Warburg, septiembre.

Pastore, A. (1995): Déficit público, a sustentabilidade das dividas interna e externa, segnoriagem e inflação: uma análise do regime monetário brasileiro, Revista de econometria, vol. 14, $\mathrm{N}^{\circ}$ 2, Rio de Janeiro, Sociedad Brasileira de Econometria.

Rabello de Castro, P. y M. Ronci (1991): Sixty years of populism in Brazil, in R. Dornbusch y S. Edwards (comps.), The Macroeconomics of Populism in Latin America, Chicago, The University of Chicago Press.

Rezende, A.L. (1990): Estabilização e reforma: 1964-1967, en M. de Paiva Abreu (comp.), A ordem do progresso: cem anos de política ecocômica republicana, 1889-1989, Rio de Janeiro, Editora Campus.

Rocha, F. (1997): Long-run limits on the Brazilian government debt, Revista brasileira de economia, vol. 51, № 4, Rio de Janeiro, Fundación Getulio Vargas, octubre/diciembre.

Sargent, T.J. y N. Wallace (1981): Some unpleasant monetarist arithmetic, Quarterly Review, vol. 5, № 3, Minneapolis, Federal Reserve Bank of Minneapolis.

Skidmore, T.E. (1988): The Politics of Military Rule in Brazil, 196485, Nueva York, Oxford University Press.

Tanner, E. (1995): Intertemporal solvency and indexed debt in Brazil: evidence from 1976-1991, Journal of International Money and Finance, vol. 14, No 4, Amsterdam, Elsevier Science, agosto.

Velloso, R. (1997): Uma proposta para acelerar o ajuste fiscal, en J.P. dos Reis Velloso (comp.), Brasil: desafios de um pais em transformação, Rio de Janeiro, Jose Olympio Editora.

Werneck, R.L.F. y A.S. Bevilaqua (1998): The Quality of the Federal Net Debt in Brazil, Texto para discussão, $N^{\circ} 385$, Rio de Janeiro, Pontificia Universidad Católica, abril.

Wilcox, D.W. (1989): The sustainability of government deficits: implications of the present-value borrowing constraint, Journal of Money, Credit, and Banking, vol. 21, N 3 , Ohio, Ohio State University Press, agosto. 